\title{
Pressure Change Of Fixed Rotational Deformities In The Femur In Human Cadaver Knees-A Biomechanical Study
}

\section{Peizhi Yuwen}

Hebei Medical University Third Affiliated Hospital

Hongzhi Lv

Hebei Medical University Third Affiliated Hospital

Yanbin Zhu

Hebei Medical University Third Affiliated Hospital

Wenli Chang

cangzhou hospital of intergated TCM-WM of hebei

Ning Wei

the fourth hospital of shijiazhuang

Jialiang Guo

Hebei Medical University Third Affiliated Hospital

Haicheng Wang

Hebei Medical University Third Affiliated Hospital

Kai Ding

Hebei Medical University Third Affiliated Hospital

Yingze Zhang

Hebei Medical University Third Affiliated Hospital

Wei Chen ( $\nabla$ drchenwei1@163.com)

Hebei Medical University Third Affiliated Hospital https://orcid.org/0000-0001-6455-0755

\section{Research article}

Keywords: Biomechanics, Contact pressure, Femur, fracture, Internal rotation deformity, External rotation deformity

Posted Date: December 10th, 2020

DOI: https://doi.org/10.21203/rs.3.rs-122625/v1

License: (c) (1) This work is licensed under a Creative Commons Attribution 4.0 International License.

Read Full License 


\section{Abstract}

Objective: To reveal the contact pressure change on tibial plateau in malalignment femur.

Methods: Fourteen adult cadaver were selected, after autopsy, 14 cadaveric knee were established and fixed at neutral position $\left(0^{\circ}\right.$, anatomically reduced), $5^{\circ}, 10^{\circ}, 15^{\circ}$ of external rotation, and $5^{\circ}, 10^{\circ}, 15^{\circ}$ of internal rotation. Connect the rotatory fixation model on the biomechanical machine and apply a vertical load to $400 \mathrm{~N}$. The contact pressure on medial and lateral tibial plateau was quantitatively measured using ultra-low-pressure sensitive film technology. FPD-305E density meter and FPD-306E pressure converter were used to read relative pressure value. Data were analyzed using SPSS software.

Results: The medial group show a significant difference on tibial plateau ( $F=92.114, P<0.01)$, further test showed statistically significant differences of pairwise comparisons between $0^{\circ}, 5^{\circ}, 10^{\circ}, 15^{\circ}$ internal rotation deformity $(P<0.05$ ). There is no significant difference in lateral group ( c $2=9.967, P<0.01$ ). The medial contact pressure is $0.940 \pm 0.177 \mathrm{MPa}$ and the lateral is $1.008 \pm 0.219 \mathrm{MPa}$ at neutral position, no statistically significant was found, so is $5^{\circ}$ of internal rotational deformity. But the medial contact pressure are all higher than the lateral side at $5^{\circ}, 10^{\circ}, 15^{\circ}$ of external rotation, and $10^{\circ}, 15^{\circ}$ of internal rotation.

Conclusion: Obvious contact pressure changes on tibial plateau were observed in rotatory deformity femur, which is closely related to the occurrence of knee osteoarthritis. Doctors should detect rotational deformity as much as possible during operation and perform anatomical reduction, for patients with residual rotational deformities, indication of osteotomy should not be too broad.

\section{Objective}

Currently, closed intramedullary interlocking nailing is standard treatment for femoral shaft fractures, though assessing intraoperatively the rotational malalignment is still a great challenge to orthopedic surgeons as tubular-shaped femur shaft enveloped by surrounding abundant muscles ${ }^{[1]}$. Many studies referred really high incidences of rotational malalignment using ultrasound or Computed Tomography (CT). Sennerich et al[2] reported $40 \%$ patients had more than $10^{\circ}$ of rotational malalignment and $16 \%$ more than $20^{\circ}$. Bråten et al[1] reported $43 \%$ more than $10^{\circ}$ and $19 \%$ more than $15^{\circ}$. Winquist et al.[3] conducted a study on 520 femoral shaft fractures treated with intramedullary nails and noticed that $8 \%$ had postoperative external rotation deformities more than $10^{\circ}$. Yang et al. ${ }^{[4]}$ reported $9.5 \%$ of 42 patients had malrotation deformities more than $15^{\circ}$.

This malalignment related to lower limb discrepancy, restriction of movement, poor muscle strength, uncoordinated movement of hip, knee, ankle and patellofemoral joints, gait disorders, etc. Which directly affect patients' daily activities, climbing stairs or running ${ }^{[5,6]}$. More worse, if it persist for years, traumatic knee steoarthritis(KOA) might be developed due to uneven force distribution on the knee $e^{[4,7,8-12]}$. Kettelkamp et al. ${ }^{[8]}$ mentioned that patients with residual femoral rotational deformities developed 
traumatic KOA and obvious local symptoms after 32 years abnormal weight bearing. However, few study focused on the force change of knee in malalighment femur, therefore we proposed this biomechanical study to reveal how contact pressure change on tibial plateau in malalighment femur through 14 rotatory fixation models.

\section{Materials And Methods}

This study has been approved by the Institutional Review Board (IRB) of the Third Hospital of Hebei Medical University.

Specimen Preparation

Fourteen fresh-frozen cadaveric lower limbs with intact soft tissue were autopsied from fourteen adult male cadavers(all cadavers were provided by the Department of Human Anatomy, Hebei Medical University), average height of the donors was $171 \mathrm{~cm}$ (range, 163 to $181 \mathrm{~cm}$ ), average age was 55 years (range, 42 to 65 years). Each cadaveric lower limb had complete femur, tibia and knee joint, there were no gross deformities of the knee, i.e. hyperflexion, hyperextension, varus and valgus. The joint can passively flex and extend without restriction. Furthermore, inner knee structures were examined by $X$ ray, pathological(osteoporosis, rheumatism, tuberculosis, or tumors) or anatomical deformities(unsymmetrical joint surface, bone hyperplasia, or other imaging abnormalities) were excluded(Fig. 1).

Then removed all muscular tissues, draw the anatomical axes along the length of the intramedullary canals of the femur and tibial based on the method proposed by Moreland et al ${ }^{[15]}$. For this biomechanical experiment, we reserved approximately $25 \mathrm{~cm}$ of the distal femur and proximal tibia and fibula, and wrapped the dissected cadaveric knee with polyethylene films to prevent dehydration and cryopreserved at $-20^{\circ} \mathrm{C}$.

Establishment of rotatory fixation model

The cadaveric knee were thawed at room temperature for 12 hours before experiment. Cut a horizontal incision about 3-4 cm long at the level of the joint space, both sides of the patellar ligament. Separate the subcutaneous fat, cut the sac, and expose the joint space, reserve anterior and posterior cruciate ligaments, as meniscus is a weight-bearing structure that can buffer pressure and affect the expansion, so it has to be preserved ${ }^{[13]}$. Then saw the femoral shaft transversely at the distal $1 / 3$ part, and guarante each cut basically at the same level to eliminate heterogeneity. Compare with the original marked axis, fix the broken ends at neutral position $\left(0^{\circ}\right.$, anatomically reduced), $5^{\circ}, 10^{\circ}, 15^{\circ}$ of external rotation, and $5^{\circ}, 10^{\circ}$, $15^{\circ}$ of internal rotation with plates and screws. Repeat the above experimental steps to complete other rotatory fixation models.

Inserted pressure-sensitive film 
An ultra-low-pressure sensitive film (0.5-2.5 MPa) is used to measure the contact pressure on tibial plateau, in order to ensure the quality of the pressure-sensitive film, we set the room humidity to $35 \% \mathrm{RH}$ and the temperature to $20^{\circ} \mathrm{C}$. Trim the pressure-sensitive film into somehow match shape according to our preliminary experiment, than seal it with a polyethylene film bag, a total thickness must be less than $250 \mu \mathrm{m}$, thereafter carefully insert it under the meniscus and fully accessed into the joint cavity, suture the capsule tightly, leakage, bending, breakage of the sealed bag mean failure ${ }^{[14]}$ (Fig. 2). In order to distinguish the anterior and posterior side of knee, the corresponding anterior side of knee on the pressure sensitive sheet is clamped with a hemostatic forceps in advance to make an impression.

Specimen Assembled to Biomechanical Testing Machine

Clamp the femur and tibial end perpendicularly and reinforce with the denture base resin and solution (type II self-setting dental powder and tray water) (Fig. 3-4). Then transfer and assemble the combination to the biomechanical testing machine (Electroforce 3520-AT, Bose company, USA). As the measurement work will be done dozens of times, so we are intended to ensure conformity between each step.

Start the biomechanical machine, load the test bench, pressurize to $200 \mathrm{~N}$ at a speed of $10 \mathrm{~N} / \mathrm{s}$ to eliminate creep. After stabilizing, apply a vertical load to the specimen to $400 \mathrm{~N}$ at a speed of $10 \mathrm{~N} / \mathrm{s}$ and uphold for 2 minutes, unload and get the pressure-sensitive film out.

FPD-305E density meter and FPD-306E pressure converter were used to read relative pressure value. we divided the contact pressure area of each pressure-sensitive film into 4 quadrants (anterolateral, anterior medial, posterior medial and posterior lateral), and 5 values of each, totally 20 values in one film.

Statistical Analysis

The experimental data were organized and computed by SPSS 21.0 software (SPSS, Chicago, IL, USA). The normality is verified using the Shapiro-Wilk test and expressed as $\pm s$, we used T-test of two independent samples to access difference between medial and lateral groups, the Student-NewmanKeuls test for pairwise comparisons between the multiple sample measurements. Using the Levene test for variance consistency, and analysis of variance (ANOVA) for random block groups. Data doesn't fit normality expressed as the median (quartile) and using Mann-Whitney Utest to access difference between medial and lateral groups. Kruskal-Wallis $\mathrm{H}$ test for random block groups, significance was $P<0.05$.

\section{Results}

The contact pressure on tibial plateau at internal and external rotation under $400 \mathrm{~N}$ vertical stress are computed and presented in Table 1-2.

The medial group show a significant difference on tibial plateau $(F=92.114, P<0.01)$, further test show statistically significant differences between neutral position and other rotational deformities $(P<0.05)$, 
significant differences between every two rotational deformities are also found. In external rotation group medial contact pressure decrease gradually with the increase degree of external rotation $(P<0.05)$. in the internal rotation group, medial contact pressure increase gradually with the increase degree of internal rotation $(P<0.05)$. However, we can't find a significant difference in lateral group $\left(c^{2}=9.967, P<0.01\right)$ (Table 2, Fig. 6).

The medial contact pressure is $0.940 \pm 0.177 \mathrm{MPa}$ and the lateral is $1.008 \pm 0.219 \mathrm{MPa}$ at neutral position, no statistically significant was found, so is $5^{\circ}$ of internal rotational deformity. While the medial contact pressure in other five groups are all higher than the lateral contact pressure(Table 3).

\section{Discussion}

As we previously mentioned that residual malrotational alignment in femur remains a gordian knot after IM surgery ${ }^{[16,17]}$. Incidences of rotational malalignment $\geq 10^{\circ}$ were as high as $41.7 \%$ compared with the unaffected side using $\mathrm{CT}^{[5]}$. Bråten et al ${ }^{[1]}$ in 1993 used ultrasound in their study and found $19 \%$ rotational malalignment of $15^{\circ}$ or more after IM nailing for femoral fractures. Tobias et al. ${ }^{[18]}$ documented $22 \%$ of 82 patients had a rotation deformity more than $15^{\circ}$ after intramedullary nails. Thoresen $\mathrm{BO}^{[19]}$ found a even higher incidence. The poor reduction of femur causes many clinical complains, due to our study, an disequilibrium joint surface is the real villains.

We created different rotational malalignment models on cadaveric femur to quantify the contact pressure in tibial plateau after distal femoral shaft fracture. In this experiment, we simulated the pressure of normal adult human when stood on one foot in a neutral position, and chose $400 \mathrm{~N}$ which is in line with the pressure load of an average human weight. We found the medial contact pressure on tibial plateau is close to the opposite side at $0^{\circ}, 5^{\circ}$ of internal rotational deformity, while at the other degree of torsional deformities, the medial contact pressure are all higher than the lateral side. As degenerative arthritis of knee are a well-known long-term complication of rotational malalignment ${ }^{[20,21]}$. Our findings just agreed with the conclusion of Foroughi et $\mathrm{al}^{[22]}$, that medial compartment of the KOA has the most significant change, its incidence rate is 10 times than lateral compartment. and Thorp's ${ }^{[23]}$ conclusion that the stress on the medial knee compartment during walking in patients with knee osteoarthritis was significantly higher than a normal person. Our biomechanical study confirm that the stress on medial tibial plateau increase in external or internal rotation deformity, and to some extent, it proves that existence of rotation deformities can increase the risk of osteoarthritis. Reasons might be the changing of intra-articular pressure and asymmetric load-bearing during movement exceeds the elastic potential energy tolerance of cartilage and subchondral bone. In addition, the original axial pressure is partially converted into shear force due to rotationary deformity, causing local biochemical cascade, aggravating the degeneration process of articular cartilage, and finally leading to knee joint TA to different degrees ${ }^{[24,25]}$.

The priority to reduce femur alignliment is detection, it can be measured clinically ${ }^{[26-30]}$ by radiography ${ }^{[31-}$ ${ }^{33]}$, ultrasound ${ }^{[1,34-36]}$, and $\mathrm{CT}^{[37-39]}$. Clinical measurements of femoral torsion is very inefficient compared 
to $\mathrm{CT}^{[34,40]}$, which is currently the method of choice because of its reliability and reproducibility. With the development and application of the navigation technique in clinics, many 2-dimensional (2D) fluoroscopy-based navigation systems have been used extensively in reducing femoral rotational deformity during operation ${ }^{[41-49]}$. Tornetta et al. ${ }^{[50]}$ corrected the femoral neck anteversion of the affected limb by using the image intensifier and taking the femoral neck anteversion of the normal hip as a control, and then corrected the potential rotational deformity. This method can correct deformities within 5 degrees and takes about 15 minutes. In addition, Yao Q et al. ${ }^{[51]}$ also carefully compared the size and shape changes of bilateral lesser trochanters and roughly judged the displacement of fracture end by applying CT influence enhancement technique during operation. Compared with the healthy side, a smaller shape of the lesser trochanter indicates external rotation displacement of the distal end, otherwise there will be internal rotation. Huang et al. ${ }^{[52]}$ performed a retrospective analysis of 13 patients with femoral shaft rotation deformity, and found that with the help of computer navigation system, the rotation deformity of femoral shaft fracture can be accurately corrected during operation, but the navigation operator should master relevant skills and pay attention to every step. Cao et al. ${ }^{[53]}$ provided quantitative parameters of femoral rotation deformity by using two-dimensional perspective navigation system and smart phone, and combined with the femoral CT value data of the healthy limb before operation.

Early detection during operation can help surgeons improving fracture reduction quality, but once rotational deformity is found after operation, osteotomy is feasible to correct this deformity. Osteotomy is a very mature treatment but the surgical indication is unclear due to patient's subjective feelings and heterogeneity between different studies. It is been well accepted that differences less than $10^{\circ}$ are generally considered normal variations, between $10^{\circ}$ and $14^{\circ}$ is a somewhat gray area referred to as possible deformity ${ }^{[34,54]}$. While Lee et al. ${ }^{[55]}$ believed that as long as the deformity is obvious, it can be corrected by osteotomy. In addition, Piper et al. ${ }^{[56]}$ believe that internal rotation deformities exceeding 10 degree can be corrected by osteotomy. Some authors ${ }^{[2,57]}$ concluded that torsional deformity of less than $20^{\circ}$ will not usually be a handicap. Other studies have found that the maximum clinical osteotomy rotation angle can be relaxed to 15 degree, as external or internal rotation deformities exceeding 15 degrees can severely affect knee joint activities and even lower limb function abnormalities ${ }^{[58]}$. Based on this study, we found that the stress on the medial side of knee joint decreased with the aggravation of external rotation deformity, and increased with the aggravation of internal rotation deformity, but both were higher than the medial side in neutral position. Doctor should pay more attention on internal rotation deformity than external rotation deformity. From our point of view that indications of osteotomy should not be too broad, though some patients can tolerate a certain degree of torsion alignment, more than 15 degrees will cause dysfunction or need to be corrected by surgery again, so it should be avoided as much as possible during the original treatment.

Certain limitations are obvious in this study, we mainly summarized in three points. Firstly, this study is based on cadaver specimens, which is not equal to normal human muscle dynamics. Therefore, the data obtained in this project may be different from human femoral rotation deformity. Secondly, the 
anatomical axis had slight different from the mechanical axis of femur. The anatomical axes are lines drawn along the length of the intramedullary canals of the femur. The mechanical axis is a line drawn from the centre of the femoral head to the centre of the talus, and is commonly referred to as Maquet's line. The anatomical axis of normal human femur refers to the line from piriformis muscle to the center of knee joint, while the mechanical axis of femur refers to the line from the center of femoral head to the center of knee joint. the femoral joint surface mechanical-anatomical (FMA) angle is about $6^{\circ}$ of valgus ${ }^{[59]}$, our study fixed the model along anatomical axis of the femur, which may increase the medial contact pressure on tibial plateau. Finally, femoral model was repeatedly used to create different rotation deformities, which may had mutual influence between each other and affect the experimental results. It is hoped that the future research will be supplemented and improved.

\section{Abbreviations}

CT

Computed Tomography

KOA

knee steoarthritis

IRB

Institutional Review Board

FMA

femoral joint surface mechanical-anatomical

2D

2-dimensional

\section{Declarations}

Ethics approval and consent to participate

This study has been approved by the Institutional Review Board (IRB) of the Third Hospital of Hebei Medical University.

Consent for publication

Not applicable.

Availability of data and materials

Not applicable.

Competing interests

The authors declare that they have no competing interests. 
Funding

The study was supported by the Non-profit Central Research Institute Fund of the Chinese Academy of Medical Sciences (2019PT320001), and the Major Research plan of National Natural Science Foundation of China (91949203)

Authors' contributions

Yuwen Peizhi and Wei Chen designed the study, Lv Hongzhi, Zhu Yanbin, Chang Wenli, Wei Ning, Guo Jialiang made substantial contributions to collect and judge all data, Yuwen Peizhi, Chen Wei, Lv Hongzhi analyzed data and performed statistical analysis; Peizhi Yuwen and Wei Chen drafted the manuscript; Wang Haicheng, Ding Kai give specific suggestions about the writing. All authors had read and approved the final manuscript.

Acknowledgements

None

\section{References}

1. Bråten $M$, Terjesen $T$, Rossvoll I. Torsional deformity after intramedullary nailing of femoral shaft fractures: measurement of femoral anteversion in 110 patients. J Bone Joint Surg Br. 1993;75:799803.

2. Sennerich T, Sutter P, Ritter G, Zapf S. Computertomographische Kontrolle des Antetorsionswinkels nach Oberschenkelschaftfrakturen des Erwachsenen [Computerized tomography follow-up of the ante-torsion angle after femoral shaft fractures in the adult][J]. Unfallchirurg. 1992;95(6):301-5.

3. Winquist RA, Hansen ST Jr, Clawson DK. Closed intramedullary nailing of femoral fractures. A report of five hundred and twenty cases. J Bone Joint Surg Am. 1984 Apr;66(4):529-39.

4. Yang KH, Han DY, Jahng JS, et al. Prevention of malrotation deformity in femoral shaft fracture[J]. J Orthop Trauma. 1998;12(8):558-62.

5. Karaman O, Ayhan E, Kesmezacar H, et al. Rotational malalignment after closed intramedullary nailing of femoral shaft fractures and its influence on daily life[J]. Eur J Orthop Surg Traumatol. 2014;24(7):1243-7.

6. Middleton S, Walker RW, Norton M. Decortication and osteotomy for the correction of multiplanar deformity in the treatment of malunion in adult diaphyseal femoral deformity: a case series and technique description[J]. Eur J Orthop Surg Traumatol. 2018;28(1):117-20.

7. Palmu SA, Lohman M, Paukku RT, et al. Childhood femoral fracture can lead to premature knee-joint arthritis[J]. Acta Orthop. 2013;84(1):71-5.

8. Kettelkamp DB, Hillberry BM, Murrish DE, et al. Degenerative arthritis of the knee secondary to fracture malunion[J]. Clinical orthopaedics and related research, 1988, (234): 159-169. 
9. Eckhoff DG, Kramer RC, Alongi CA, et al. Femoral anteversion and arthritis of the knee[J]. J Pediatr Orthop. 1994;14(5):608-10.

10. Greenwood DC, Muir KR, Doherty M, et al. Conservatively managed tibial shaft fractures in Nottingham, UK: are pain, osteoarthritis, and disability long-term complications?[J]. J Epidemiol Community Health. 1997;51(6):701-4.

11. Kumar A, Whittle AP. Treatment of complex (Schatzker Type VI) fractures of the tibial plateau with circular wire external fixation: retrospective case review[J]. J Orthop Trauma. 2000;14(5):339-44.

12. Papagelopoulos PJ, Partsinevelos AA, Themistocleous GS, et al. Complications after tibia plateau fracture surgery[J]. Injury. 2006;37(6):475-84.

13. Fukubayashi T, Kurosawa $\mathrm{H}$. The contact area and pressure distribution pattern of the knee. A study of normal and osteoarthrotic knee joints[J]. Acta Orthop Scand. 1980;51(6):871.

14. Bedi A, Kelly NH, Baad M, et al. Dynamic contact mechanics of the medial meniscus as a function of radial tear, repair, and partial meniscectomy[J]. J Bone Joint Surg Am. 2010;92(6):1398-408.

15. Moreland JR, Bassett LW, Hanker GJ. Radiographic analysis of the axial alignment of the lower extremity[J]. J Bone Joint Surg Am. 1987;69(5):745-9.

16. Rippstein J. Zur bestimmung der antetorsion des schenkelhalses mittels zweier Röntgenaufnahmen[J]. Z Orthop. 1955;86:345-60.

17. Bråten $\mathrm{M}$, Terjesen $\mathrm{T}$, Rossvoll I. Femoral anteversion in normal adults:ultrasound measurements in 50 men and 50 women[J]. Acta Orthop Scand. 1992;63:29-32.

18. Hufner T, Citak $M$, Suero EM, et al. Femoral malrotation after unreamed intramedullary nailing: an evaluation of influencing operative factors[J]. J Orthop Trauma. 2011;25(4):224-7.

19. Thoresen BO, Alho A, Ekeland A, et al. Interlocking intramedullary nailing in femoral shaft fractures. A report of forty-eight cases[J]. J Bone Joint Surg Am. 1985;67(9):1313-20.

20. Eckhoff DG, Kramer RC, Alongi CA, et al. Femoral anteversion and arthritis of the knee[J]. J Pediatr Orthop. 1994;14:608-10.

21. Bellabarba C, Ricci WM, Bolhofner BR. Indirect reduction and plating of distal femoral nonunions[J]. J Orthop Trauma. 2002;16:287-96.

22. Foroughi N, Smith R, Vanwanseele B. The association of external knee adduction moment with biomechanical variables in osteoarthritis: A systematic review[J]. Knee. 2009;16(5):303.

23. Thorp LE, Sumner DR, Wimmer MA, et al. Relationship between pain and medial knee joint loading in mild radiographic knee osteoarthritis[J]. Arthritis Care Res. 2007;57(7):1254-60.

24. Chew MW, Henderson B, Edwards JC. Antigen-induced arthritis in the rabbit: ultrastructural changes at the chondrosynovial junction[J]. Int J Exp Pathol. 1990;71(6):879.

25. 53. Hamerman D. The biology of osteoarthritis[J]. N Engl J Med, 1989, 320 (20): 1322.

26. Alho A, Strømsøe K, Ekeland A. Locked intramedullary nailing of femoral shaft fractures[J]. J Trauma. 1991;31:49-59. 
27. Johnson KD, Greenberg M. Comminuted femoral shaft fractures[J]. Orthop Clin North Am. 1987;18:133-47.

28. Kempf I, Grosse A, Beck G. Closed locked intramedullary nailing, its application to comminuted fractures of the femur[J]. J Bone Joint Surg Am. 1985;67A:709-20.

29. Ruwe PA, Gage JR, Ozonoff MB, et al. Clinical determination of femoral anteversion: a comparison with esthablished techniques[J]. J Bone Joint Surg Am. 1992;6:820-30.

30. Wiss DA, Fleming $\mathrm{CH}$, Matta JM, et al. Comminuted and rotationally unstable fractures of the femur treated with an interlocking nail[J]. Clin Orthop. 1986;212:35-47.

31. Dunlap K, Shands AR Jr, Hollister LC Jr, et al. A new method for determination of torsion of the femur[J]. J Bone Joint Surg Am. 1953;35A:289-311.

32. Dunn DM. Anteversion of the neck of the femur: a method of measurement[J]. J Bone Joint Surg Br. 1952;34B:181-6.

33. Rippstein J. Zur bestimmung der antetorsion des schenkelhalses mittels zweier Röntgenaufnahmen[J]. Z Orthop. 1955;86:345-60.ãष冈.

34. Bråten $\mathrm{M}$, Terjesen T, Rossvoll I. Femoral anteversion in normal adults: ultrasound measurements in 50 men and 50 women[J]. Acta Orthop Scand. 1992;63:29-32.

35. Ehrenstein T, Rikli DA, Peine R, et al. A new ultrasound-based method for the assessment of torsional differences following closed intramedullary nailing of femoral fractures[J]. Skel Radiol. 1999;28:336-41.

36. Terjesen T, Anda S, Svenningsen S. Femoral anteversion in adolescents and adults measure by ultrasound[J]. Clin Orthop. 1990;256:274-9.

37. Jeanmart L, Baert AL, Wackenheim A. Computer Tomography of Neck, Chest, Spine and Limbs. Atlas of Pathologic Computer Tomography[M]. Vol. 3. New York: Springer-Verlag; 1983. pp. 171-7.

38. Strecker W, Franzreb M, Pfeiffer T, et al. Computerized tomography measurement of torsion angle of the lower extremities[J]. Unfallchirurg. 1994;97:609-13.

39. Wissing H, Spira G. Determination of rotational defects of the femur by computer tomographic determination of antetorsion angle of the femoral neck[J]. Unfallchirurg. 1986;12:1-11.

40. Svenningsen S, Apalset K, Terjesen T, et al. Regression of femoral anteversion: a prospective study of intoeing children[J]. Acta Orthop Scand. 1989;60:170-3.

41. Crowl AC, Kahler DM. Closed reduction and percutaneous fixation of anterior column acetabular fractures. Comput Aided Surg. 2002;7:169-78.

42. Mouhsine E, Garofalo R, Borens 0 , et al. Percutaneous retrograde screwing for stabilisation of acetabular fractures[J]. Injury. 2005;36:1330-6.

43. Gao H, Luo CF, Hu CF, Zhang CQ, Zeng BF. Percutaneous screw fixation of acetabular fractures with 2-D fluoroscopy-based computerized navigation[J]. Arch Orthop Trauma Surg. 2010;130:1177-83.

44. Gao H, Luo CF, Hu CF, Zhang CQ, Zeng BF. Minimally invasive fluoro-navigation screw fixation for the treatment of pelvic ring injuries[J]. Surg Innov. 2011;18:279-84. 
45. Mosheiff R, Weil Y, Peleg E, Liebergall M. Computerised navigation for closed reduction during femoral intramedullary nailing[J]. Injury. 2005;36:866-70.

46. Khoury A, Liebergall M, Weil Y, Mosheiff R. Computerized fluoroscopicbased navigation-assisted intramedullary nailing[J]. Am J Orthop. 2007;36:582-5.

47. Grützner PA, Suhm N. Computer aided long bone fracture treatment[J]. Injury. 2004;35(suppl 1):SA57-S-A64.

48. Suhm N, Messmer P, Zuna I, Jacob LA, Regazzoni P. Fluoroscopic guidance versus surgical navigation for distal locking of intramedullary implants: a prospective, controlled clinical study[J]. Injury. 2004;35:567-74.

49. Wilharm A, Gras F, Rausch S, et al. Navigation in femoralshaft fractures-from lab tests to clinical routine[J]. Injury. 2011;42:1346-52.

50. Tornetta P 3rd, Ritz G, Kantor A. Femoral torsion after interlocked nailing of unstable femoral fractures[J]. J Trauma. 1995;38(2):213-9.

51. Yao Q, Tang PF, Huang P, et al. CT scan to measure fracture malrotation after interlocking intramedullary nailing of femoral fracture[J]. Orthop J China. 2007;15(4):260-2..(chinese).

52. Huang JH, Cao JQ, Zhu B, et al. A nonvel computer-assisted navigation for intraoperative correction of femoral rotation deformity in diaphyseal fractures[J]. China J Orthop Trauma. 2017;19(4):286. -292.62 (chinese).

53. Cao JQ, Huang JH, Yuan T, et al. Intraoperative Correction of Femoral Rotational Deformity Using a Conventional Navigation System and a Smartphone: A Novel Technique[J]. Surg Innov. 2017;24(5):446-54.

54. Wang Yc M, Jm G, Zh, Editor-in-Chief. Bone and Joint Injury[M]. Second Edition. Beijing: People's Medical Publishing House, 1990. 71-72.

55. Lee SY, Jeong J, Lee K, et al. Unexpected angular or rotational deformity after corrective osteotomy[J]. BMC Musculoskelet Disord. 2014;15:175.

56. Piper K, Chia M, Graham E. Correcting rotational deformity following femoral nailing[J]. Injury. 2009;40(6):660-2.

57. Yokozeki K. A Study on Alignment of Comminuted Femoral Fractures Treated by Interlocking Cylinder Nailing[J]. Kitasato Medicine. 1992;22:20-8.

58. Citak M, Kendoff D, Gardner MJ, et al. Rotational stability of femoral osteosynthesis in femoral fractures - navigated measurements[J]. Technol Health Care. 2009;17(1):25-32.

59. Abdel MP, Oussedik S, Parratte S, Lustig S, Haddad FS. Coronal alignment in total knee replacement: historical review, contemporary analysis, and future direction[J]. Bone Joint J. 2014;96-B(7):857-62.

\section{Tables}


Table 1

Contact pressure value of medial tibial plateau at various rotation deformity (MPa)

\begin{tabular}{|c|c|c|c|}
\hline Rotation deformity & Average contact pressure(Mpa) & $\mathbf{F}$ & $\mathbf{P}$ \\
\hline Neutral position $\left(0^{\circ}\right)$ & $0.952 \pm 0.168$ & \multirow[t]{7}{*}{92.114} & \multirow[t]{7}{*}{$0.000^{*}$} \\
\hline external rotation $5^{\circ}$ & $1.601 \pm 0.093$ & & \\
\hline external rotation $10^{\circ}$ & $1.472 \pm 0.075$ & & \\
\hline external rotation $15^{\circ}$ & $1.172 \pm 0.096$ & & \\
\hline internal rotation $5^{\circ}$ & $1.151 \pm 0.082$ & & \\
\hline internal rotation $10^{\circ}$ & $1.493 \pm 0.085$ & & \\
\hline internal rotation $15^{\circ}$ & $1.645 \pm 0.088$ & & \\
\hline
\end{tabular}

Table 2

Contact pressure value of lateral tibial plateau at various rotation deformity (MPa)

\begin{tabular}{|llll|}
\hline Rotation deformity & Average contact pressure(Mpa) & $\chi^{2}$ & P \\
\hline Neutral position $\left(0^{\circ}\right)$ & $1.023 \pm 0.208$ & 9.967 & 0.126 \\
\hline external rotation $5^{\circ}$ & $1.141 \pm 0.208$ & & \\
\hline external rotation $10^{\circ}$ & $1.209 \pm 0.121$ & & \\
external rotation $15^{\circ}$ & $1.067(0.206)$ & & \\
\hline internal rotation $5^{\circ}$ & $1.098 \pm 0.333$ & & \\
\hline internal rotation $10^{\circ}$ & $1.221(0.225)$ & & \\
\hline internal rotation $15^{\circ}$ & $1.114 \pm 0.243$ & & \\
\hline
\end{tabular}

Table 3

Comparison of contact pressure between medial and lateral tibial plateau

\begin{tabular}{|c|c|c|c|c|c|c|c|}
\hline & $\begin{array}{l}\text { Neutral } \\
\text { position }\left(0^{\circ}\right)\end{array}$ & $\begin{array}{l}\text { external } \\
\text { rotation } \\
5^{\circ}\end{array}$ & $\begin{array}{l}\text { external } \\
\text { rotation } \\
10^{\circ}\end{array}$ & $\begin{array}{l}\text { external } \\
\text { rotation } \\
15^{\circ}\end{array}$ & $\begin{array}{l}\text { internal } \\
\text { rotation } 5^{\circ}\end{array}$ & $\begin{array}{l}\text { internal } \\
\text { rotation } \\
10^{\circ}\end{array}$ & $\begin{array}{l}\text { internal } \\
\text { rotation } \\
15^{\circ}\end{array}$ \\
\hline$t / Z$ & 0.998 & -7.525 & -6.909 & -2.160 & -0.578 & -4.251 & -7.673 \\
\hline $\mathrm{P}$ & 0.327 & $0.000^{*}$ & $0.000^{*}$ & $0.031^{*}$ & 0.572 & $0.000^{*}$ & $0.000^{*}$ \\
\hline
\end{tabular}




\section{Figures}

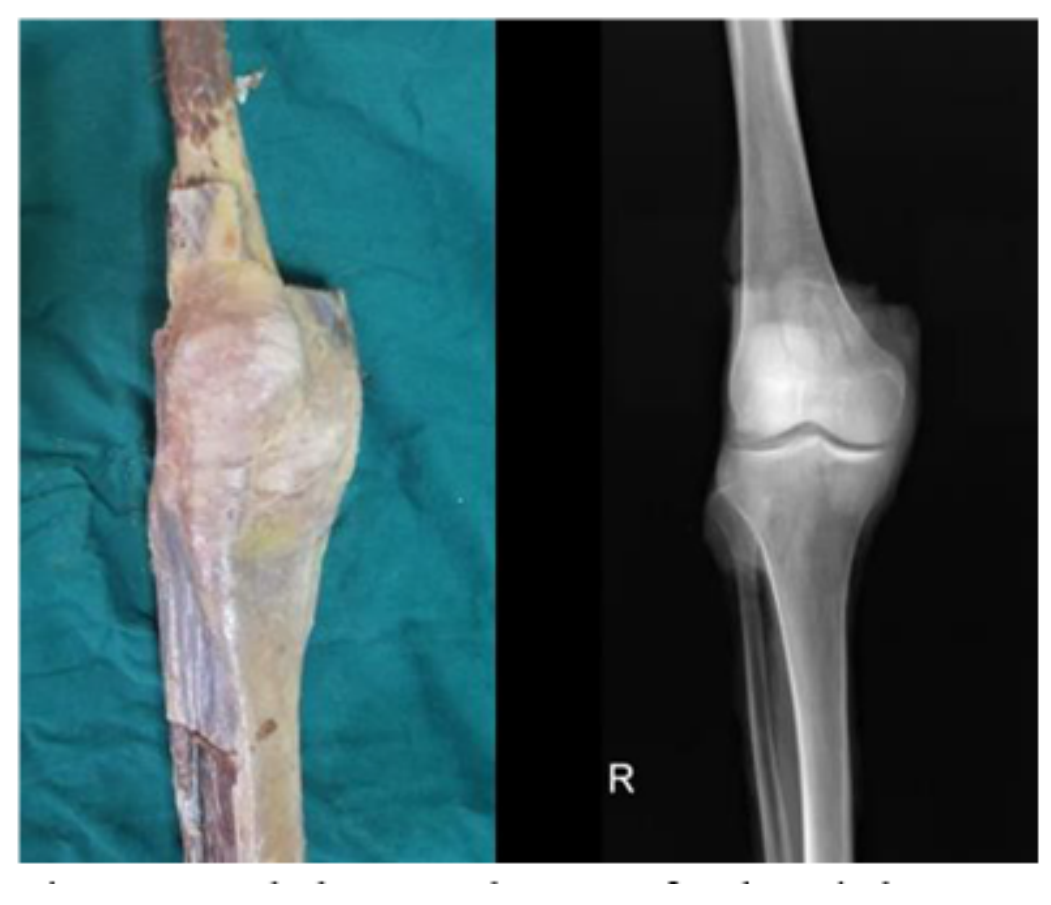

Figure 1

General photos and X-ray of cadaveric knee

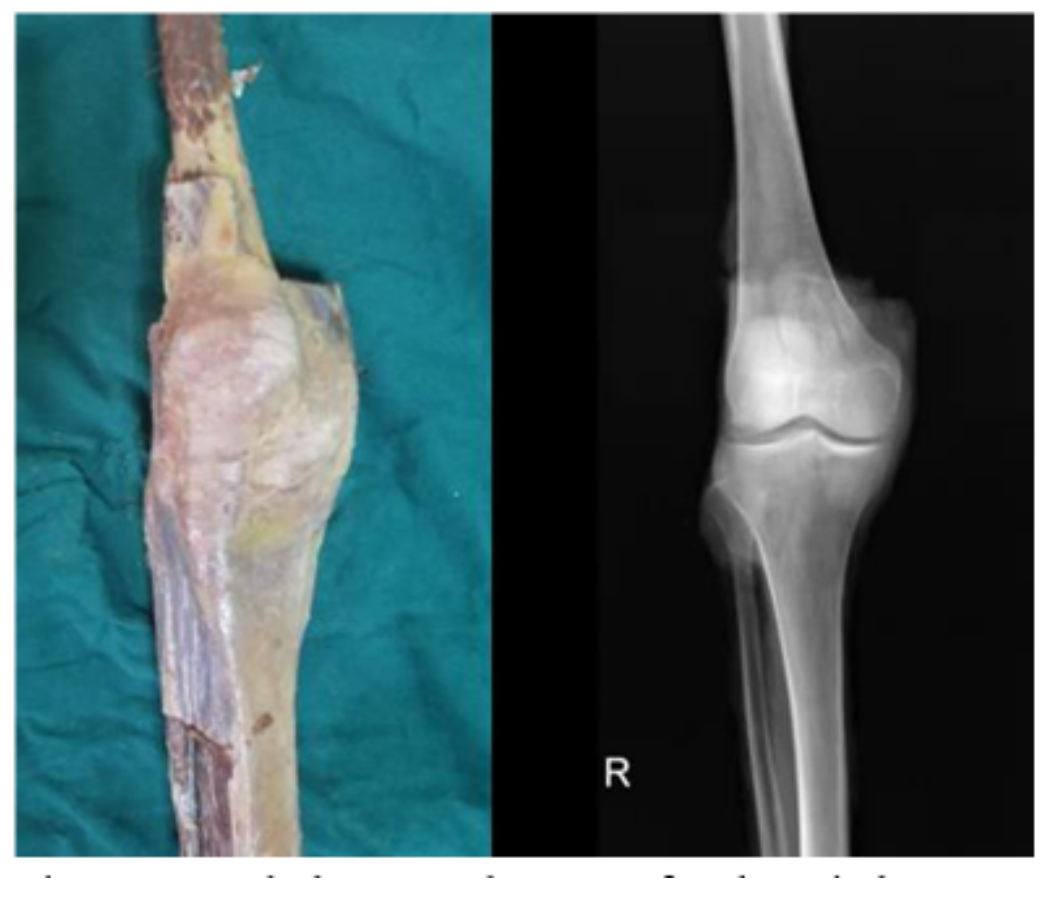

Figure 1

General photos and X-ray of cadaveric knee 


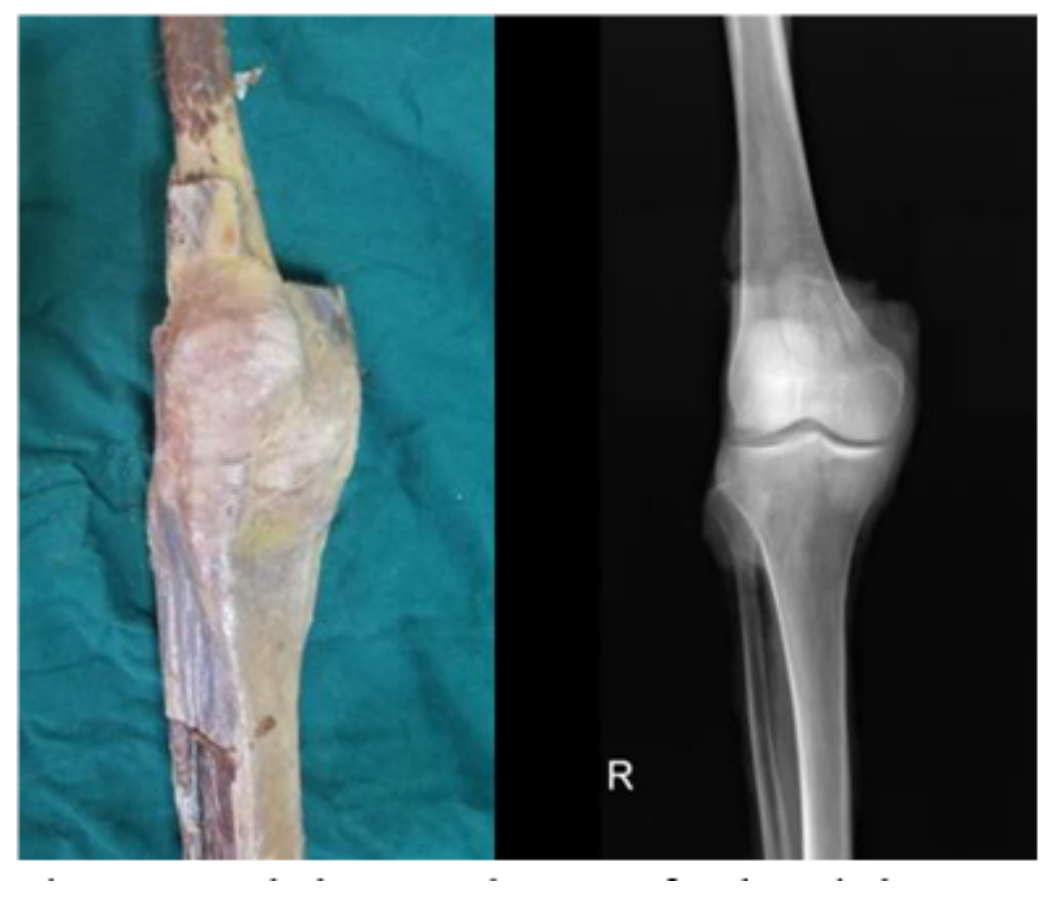

Figure 1

General photos and X-ray of cadaveric knee

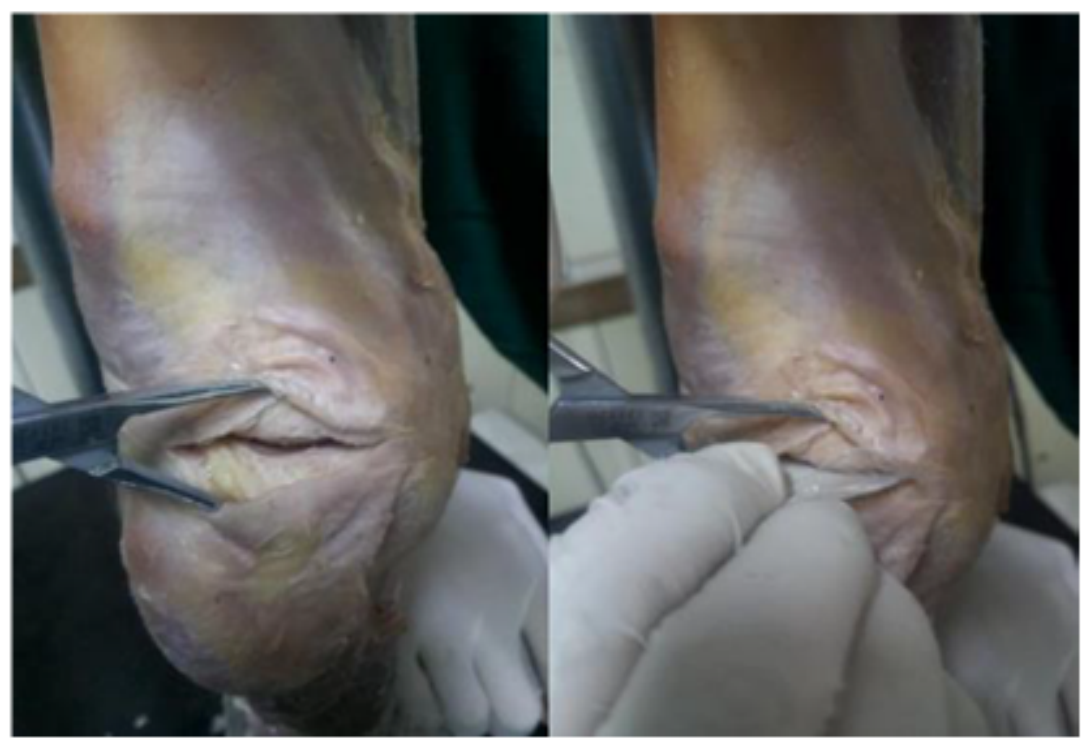

Figure 2

Insert ultra-low-pressure sensitive film 


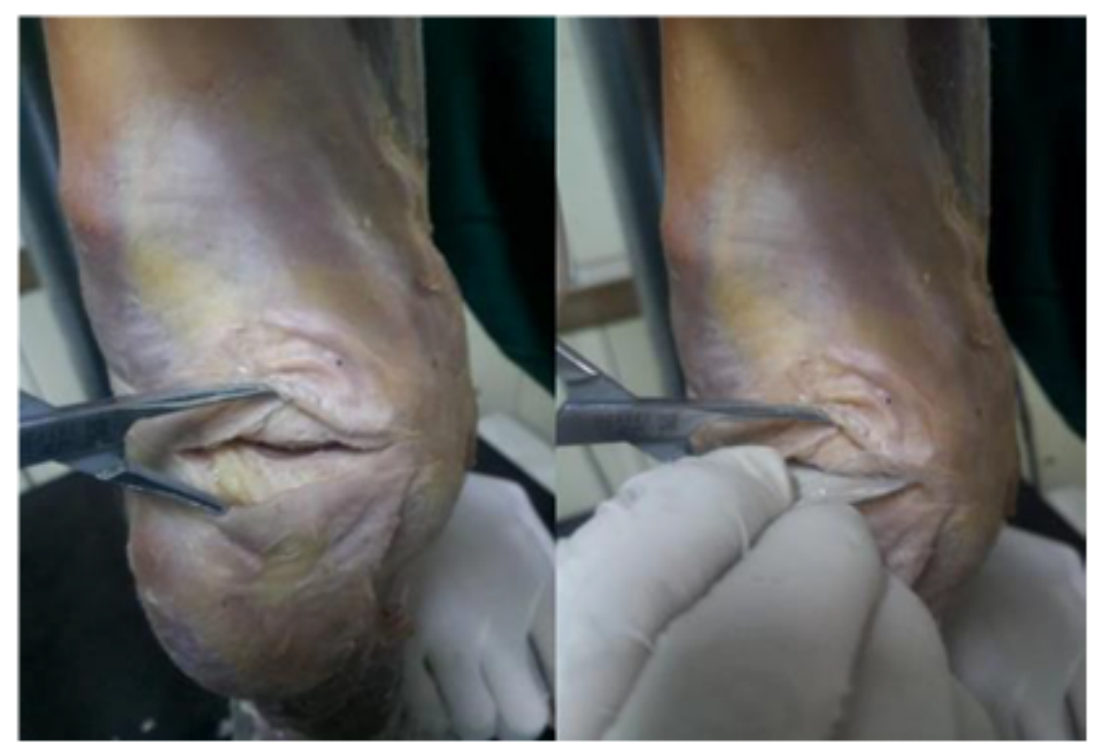

Figure 2

Insert ultra-low-pressure sensitive film

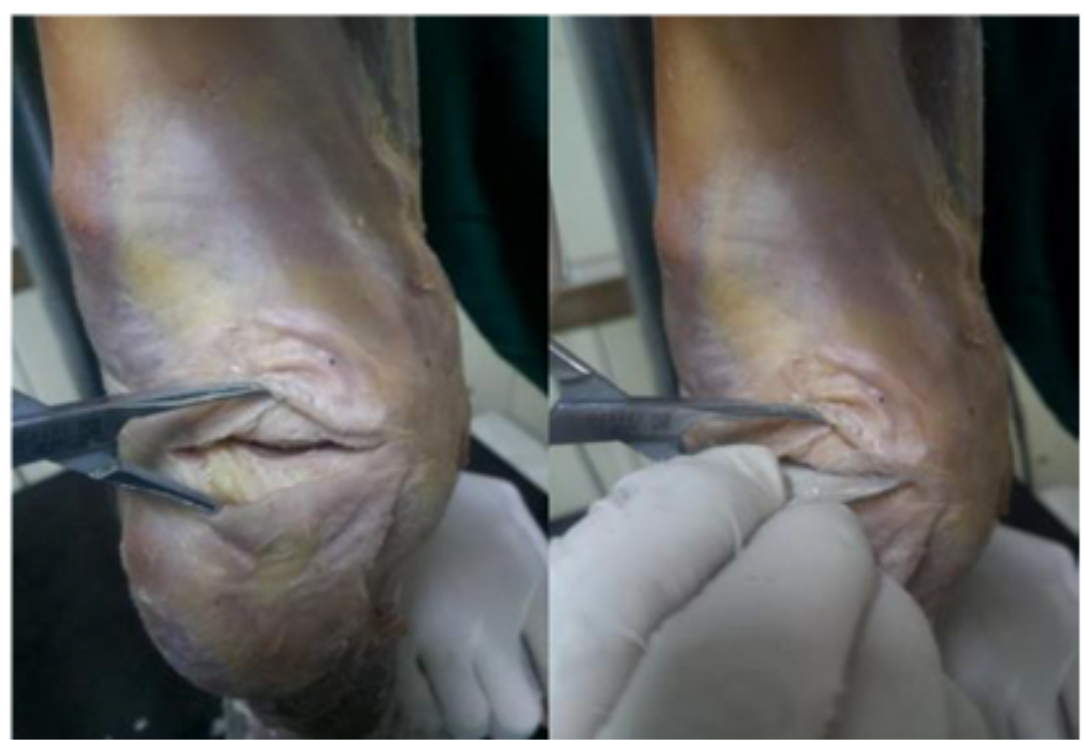

Figure 2

Insert ultra-low-pressure sensitive film 


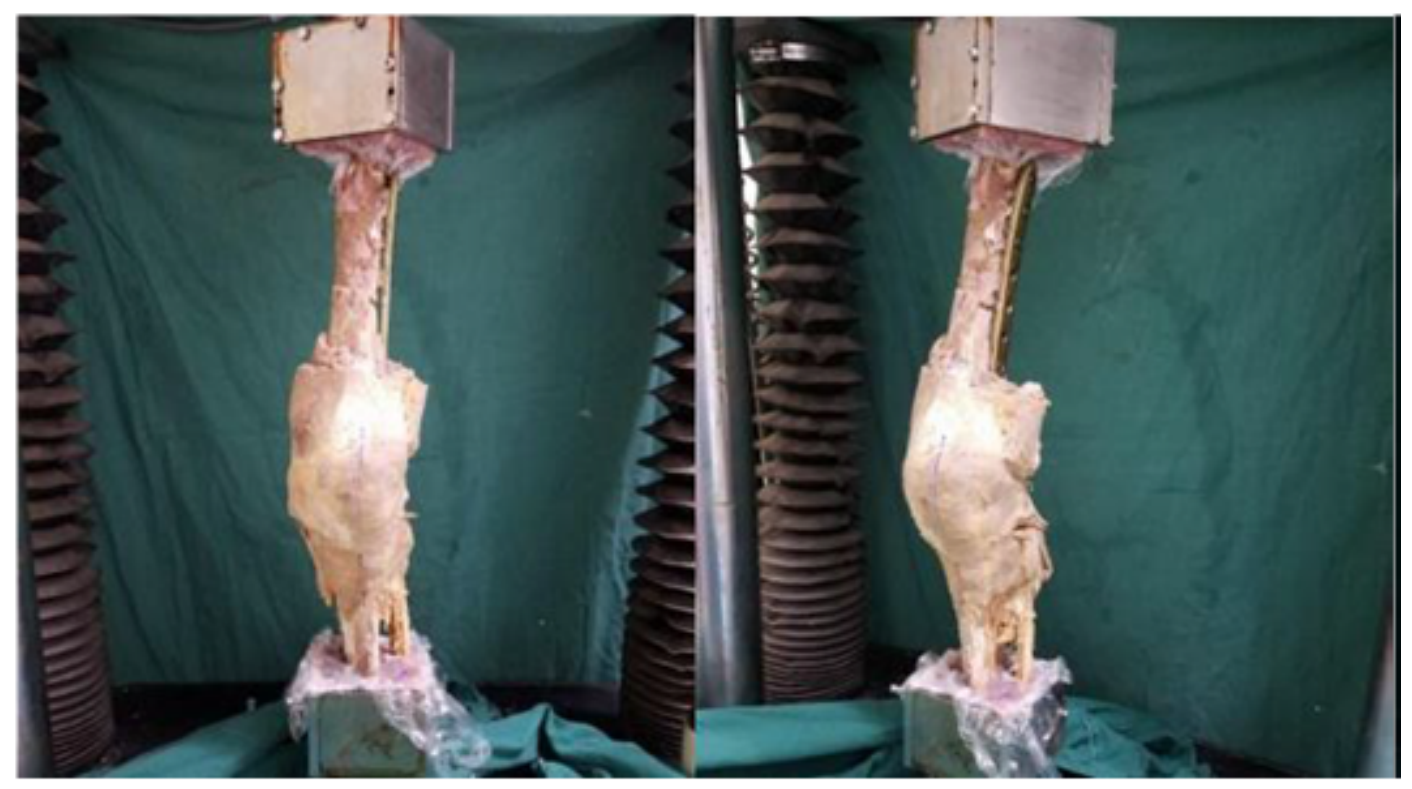

Figure 3

The specimens were assembled to the BOSE Electroforce 3520-AT biomechanical testing machine, and the femoral and tibia stumps was adjusted so that the lower limb mechanical axis was close to naturally standing position. Fig.3 Model of external rotation deformity,

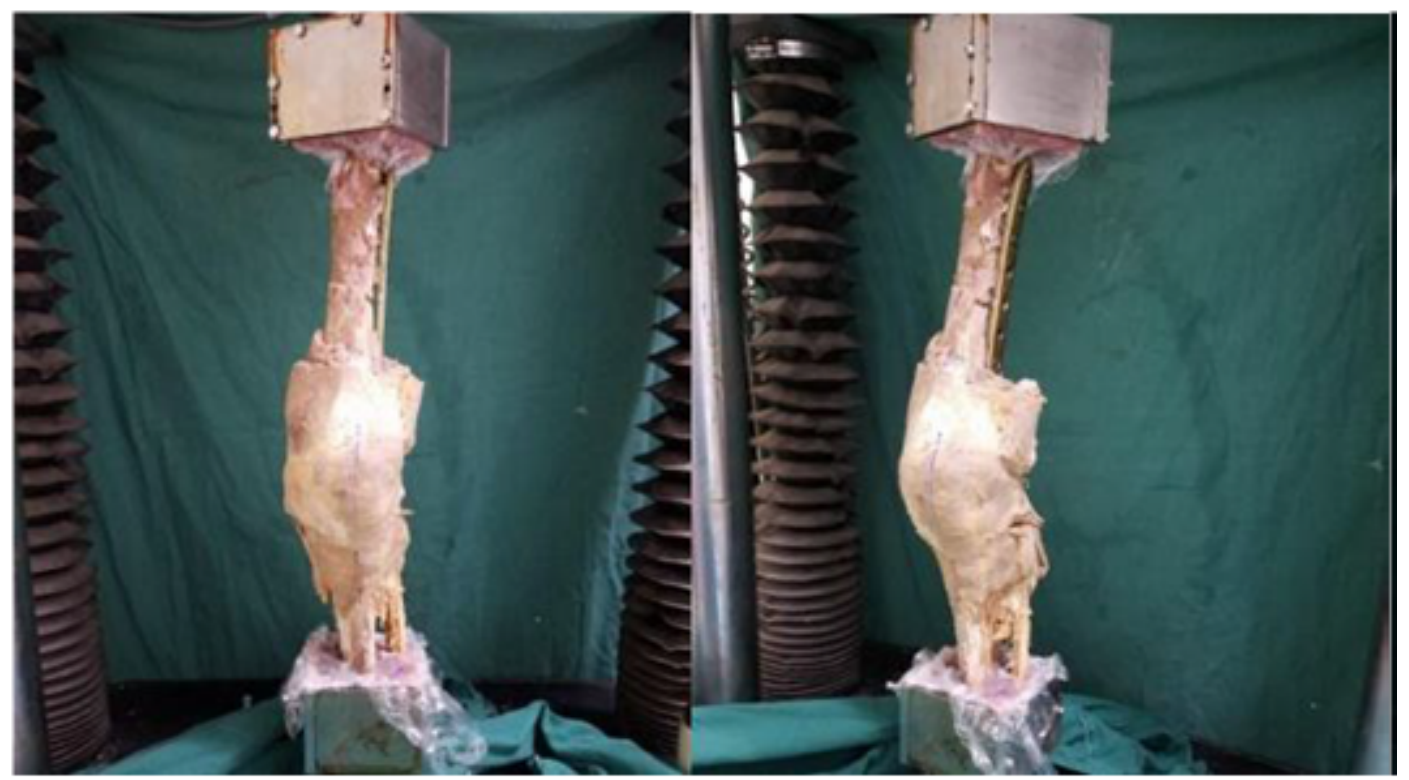

\section{Figure 3}

The specimens were assembled to the BOSE Electroforce 3520-AT biomechanical testing machine, and the femoral and tibia stumps was adjusted so that the lower limb mechanical axis was close to naturally standing position. Fig.3 Model of external rotation deformity, 


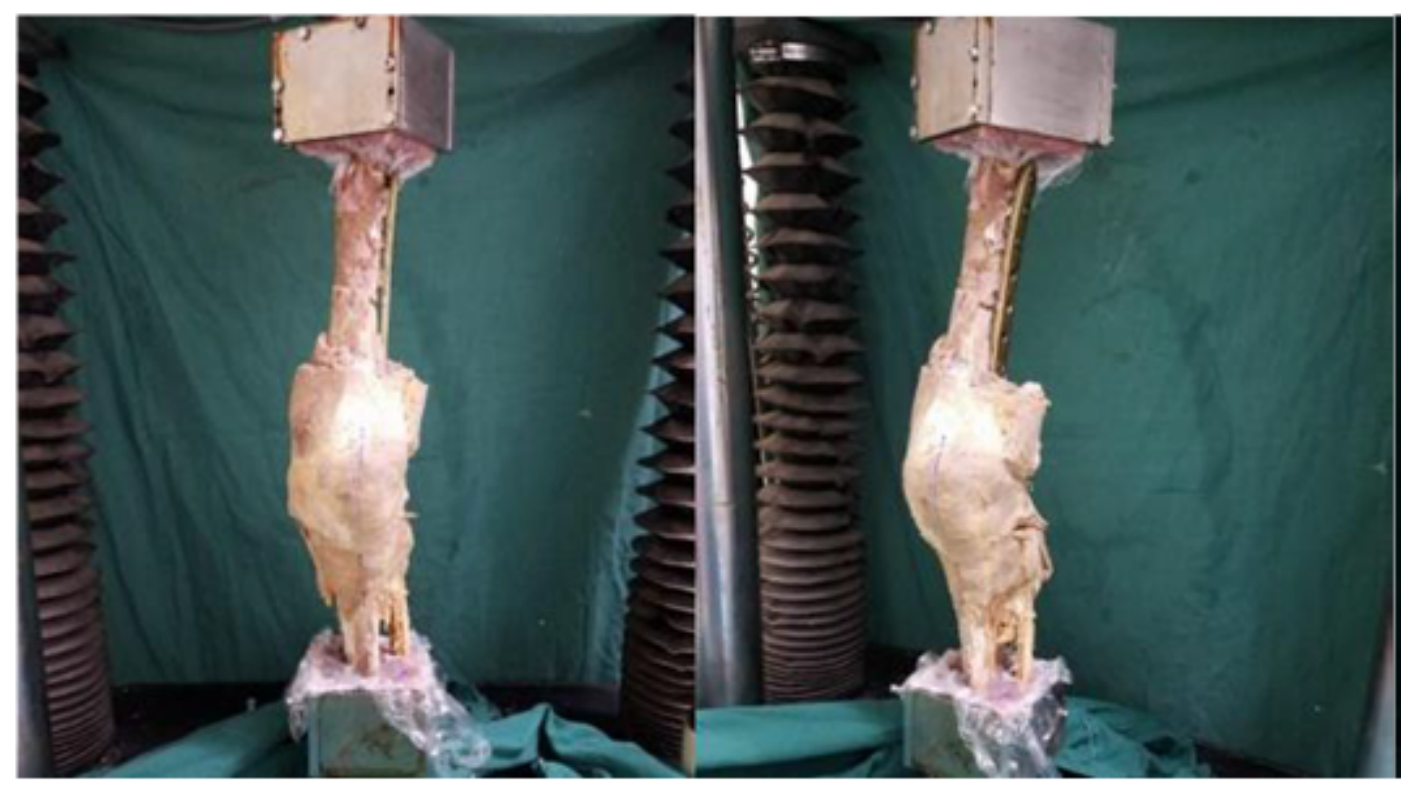

\section{Figure 3}

The specimens were assembled to the BOSE Electroforce 3520-AT biomechanical testing machine, and the femoral and tibia stumps was adjusted so that the lower limb mechanical axis was close to naturally standing position. Fig.3 Model of external rotation deformity,

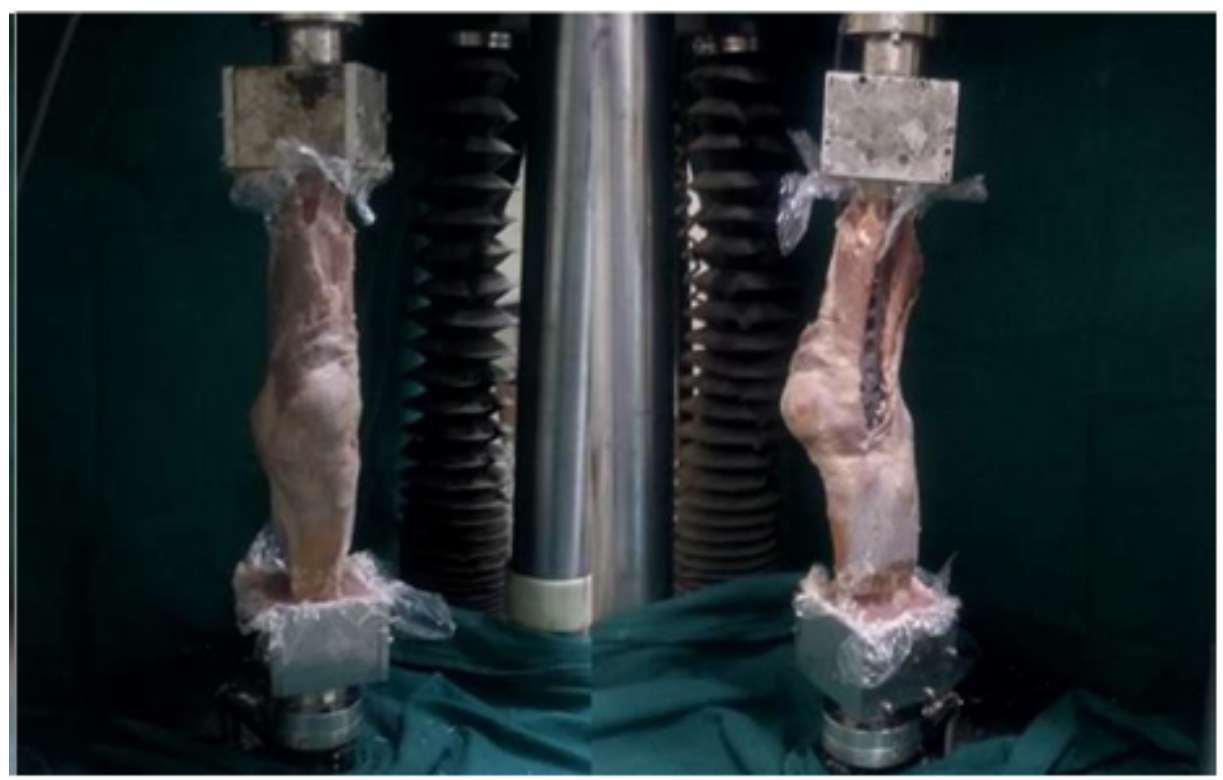

\section{Figure 4}

The specimens were assembled to the BOSE Electroforce 3520-AT biomechanical testing machine, and the femoral and tibia stumps was adjusted so that the lower limb mechanical axis was close to naturally standing position. Fig.4 Model of internal rotation deformity 


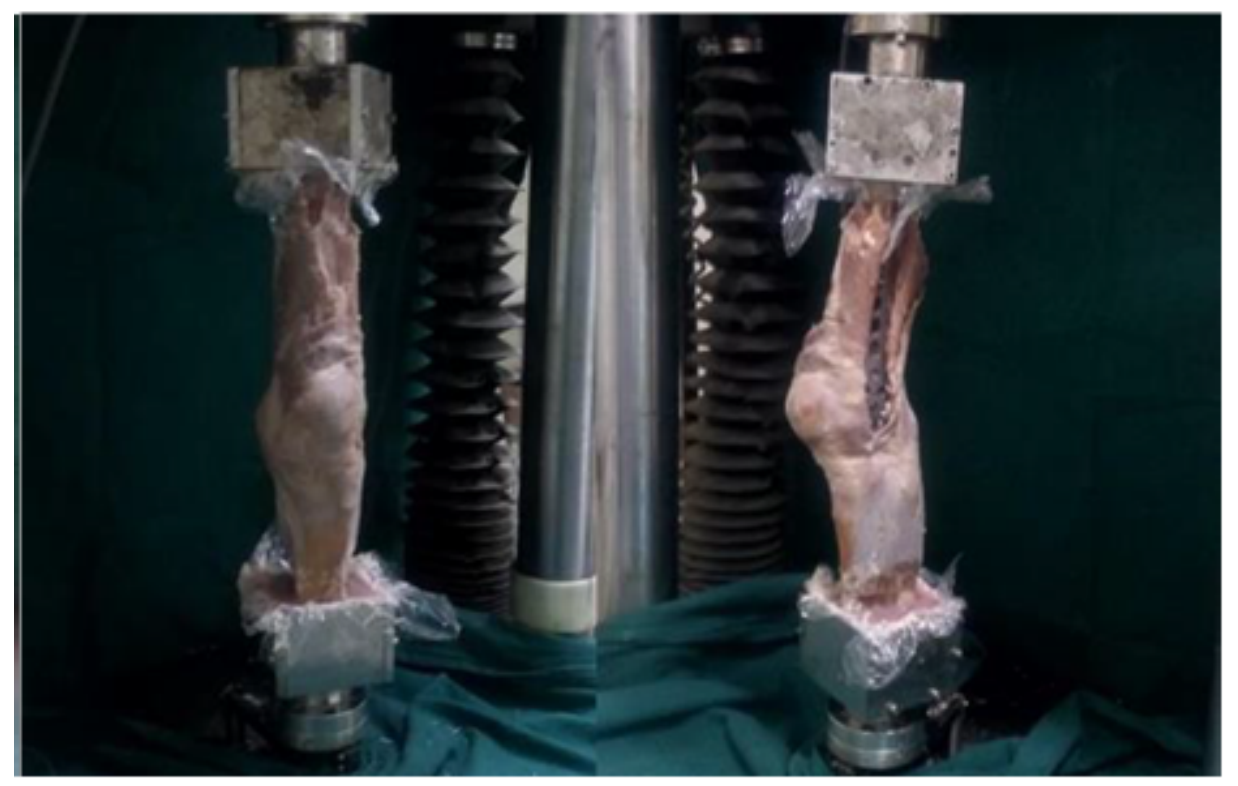

\section{Figure 4}

The specimens were assembled to the BOSE Electroforce 3520-AT biomechanical testing machine, and the femoral and tibia stumps was adjusted so that the lower limb mechanical axis was close to naturally standing position. Fig.4 Model of internal rotation deformity

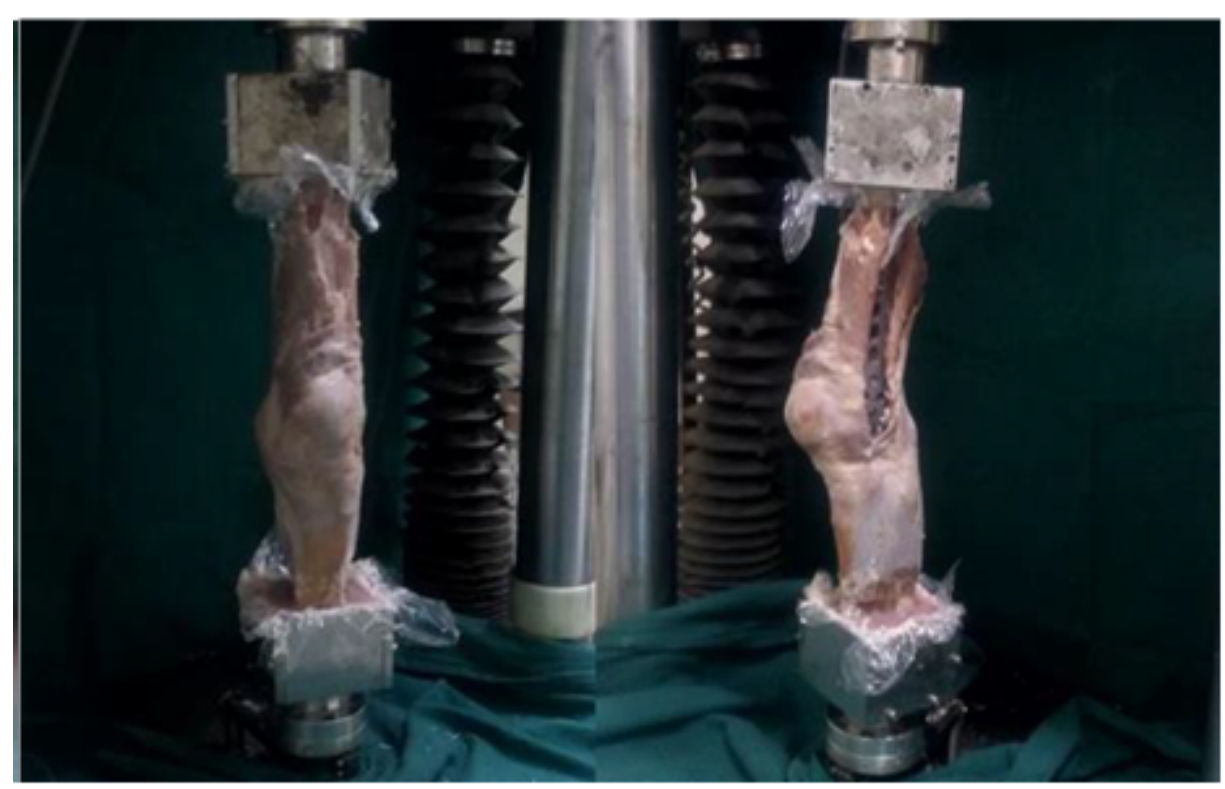

\section{Figure 4}

The specimens were assembled to the BOSE Electroforce 3520-AT biomechanical testing machine, and the femoral and tibia stumps was adjusted so that the lower limb mechanical axis was close to naturally standing position. Fig.4 Model of internal rotation deformity 

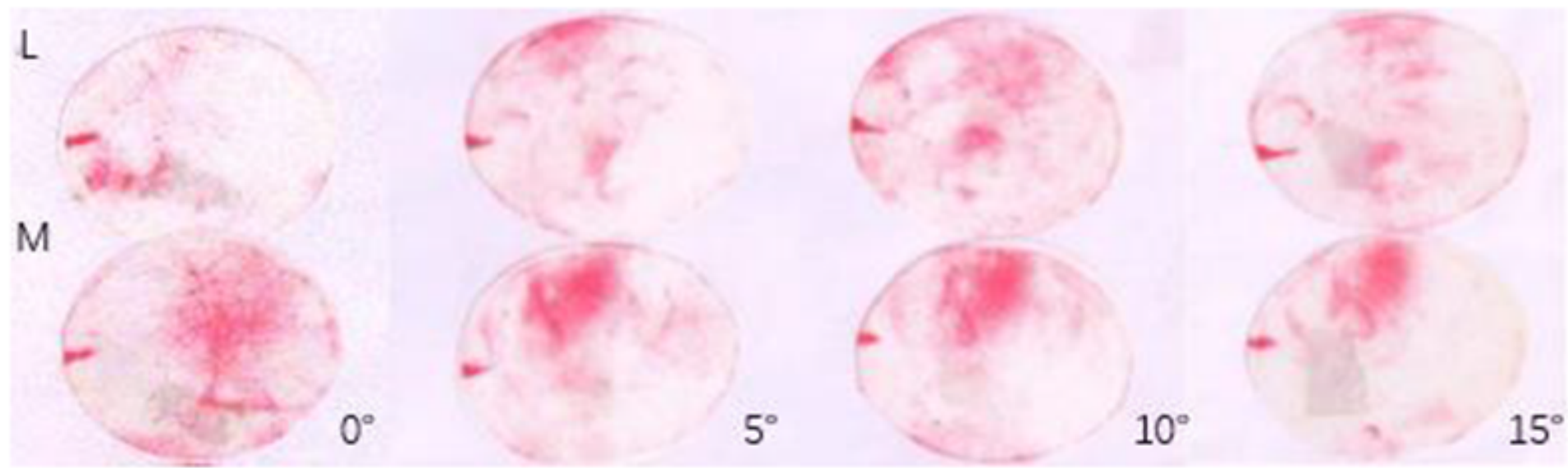

\section{Figure 5}

Ultra-low-pressure sensitive film of all external rotation deformities L: Lateral part; M: Medial part
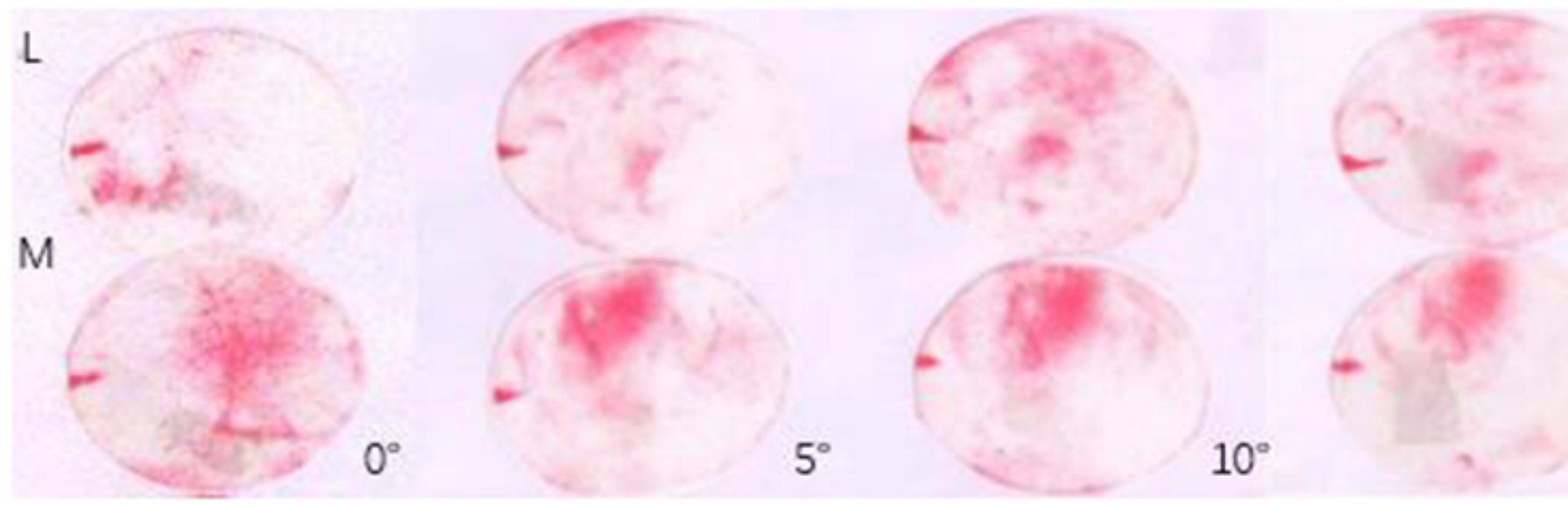

\section{Figure 5}

Ultra-low-pressure sensitive film of all external rotation deformities L: Lateral part; M: Medial part
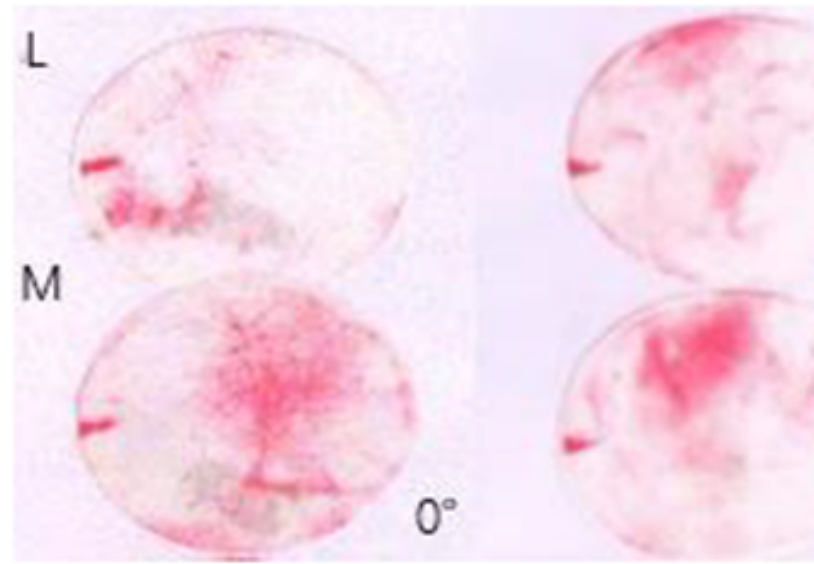

Figure 5 
Ultra-low-pressure sensitive film of all external rotation deformities L: Lateral part; M: Medial part
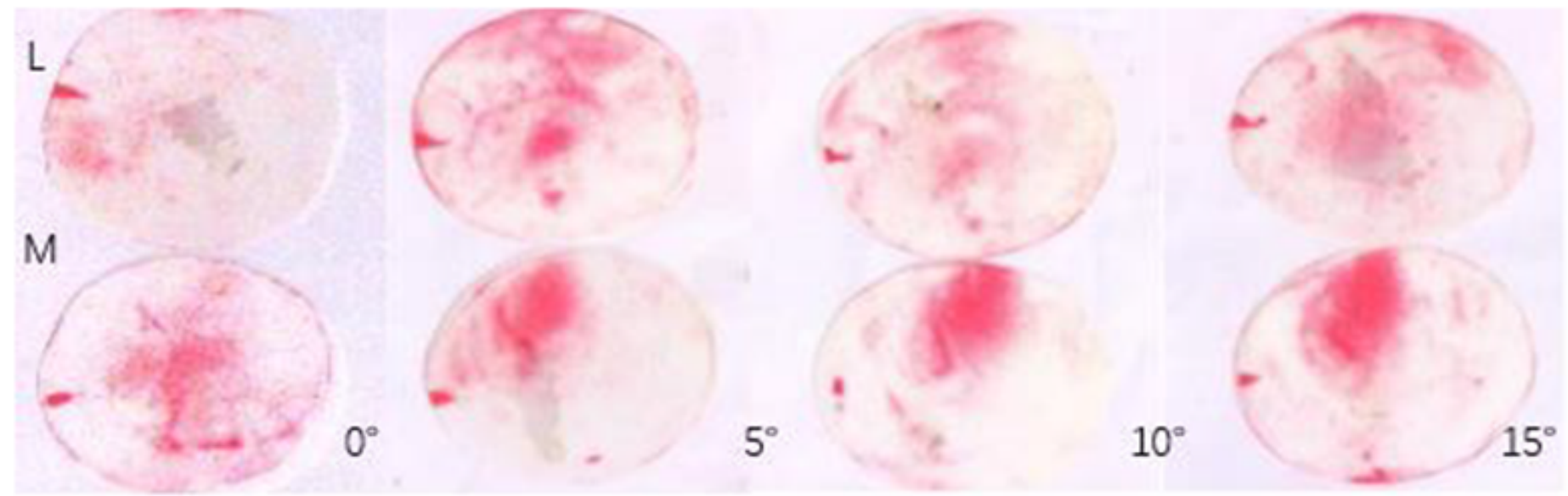

Figure 6

Ultra-low-pressure sensitive film of all internal rotation deformities L: Lateral part; M: Medial part

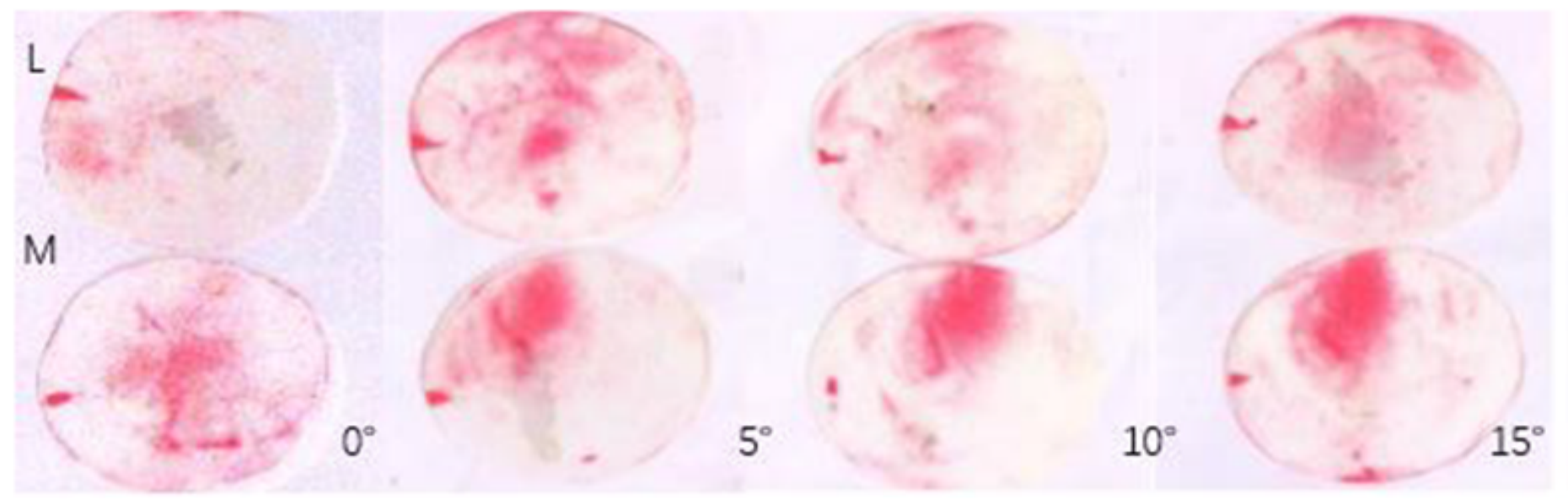

\section{Figure 6}

Ultra-low-pressure sensitive film of all internal rotation deformities L: Lateral part; M: Medial part
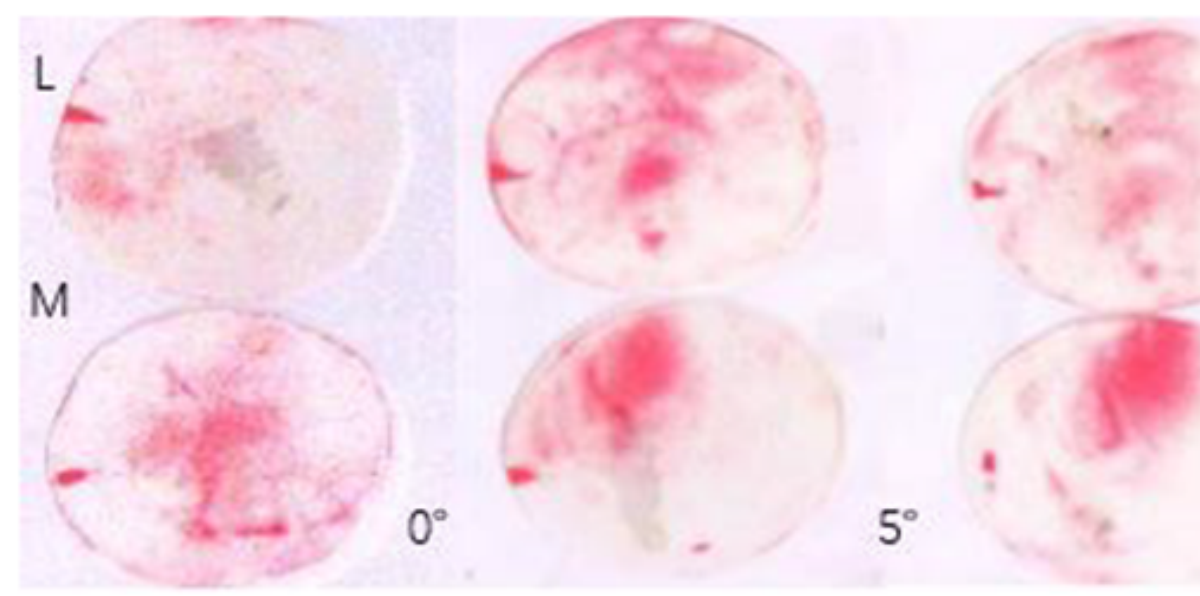

$10^{\circ}$
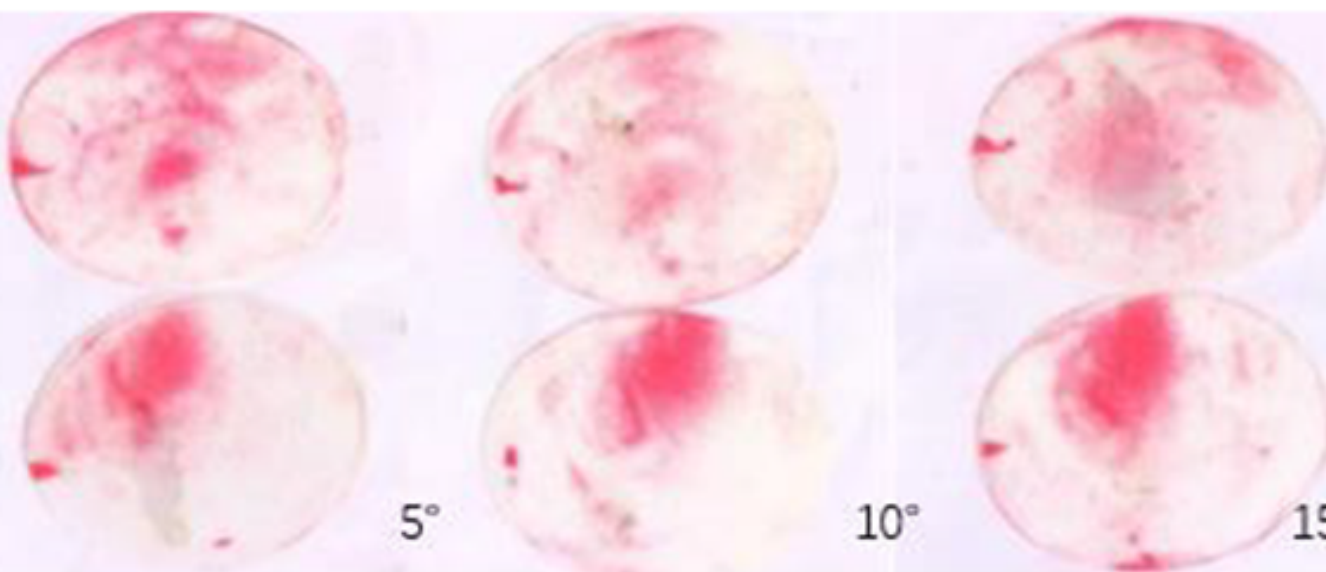
Figure 6

Ultra-low-pressure sensitive film of all internal rotation deformities L: Lateral part; M: Medial part 